\title{
El exilio en la pantalla: Internet, identidad y refugiados
}

\author{
Maider Iriarte \\ Universitat Oberta de Catalunya \\ miriarte@uoc.edu
}

One man's imagined community, is another man's political prison.

Arjun Appadurai

Hace algunos meses, me sorprendí una mañana consultando a través de Internet la prensa del corazón española en mi casa en Viena. La anécdota no hubiera tenido más importancia si no fuera porque, hasta entonces, nunca me habían interesado ni lo más mínimo los problemas sentimentales de la gente famosa. El hecho llamó mi atención y me llevó a reflexionar sobre las causas de aquel cambio. Por aquella época, llevaba casi un año y medio viviendo en Austria y sin volver al País Vasco. Fue entonces, cuando tomé conciencia de que todo aquel tiempo sin hablar mi lengua, sin compartir conversaciones triviales en la frutería o el ascensor, sin pasear por las calles en las que crecí, había desencadenado un proceso dentro de mí del que mi repentino interés por la prensa rosa no era más que un reflejo. Descubrí que aquel exilio voluntario al que me había sometido me estaba desgastando hasta el punto de que necesitaba "recordarme" quién era y de dónde venía y, lo que era aún más importante, "sentir" que seguía cerca de mi país. Algo que Internet hacía posible.

Me pregunté por qué mi mente necesitaba esas anclas, qué influencia tenían en mí y en mi día a día, en mi forma de pensarme y pensar, en mis esfuerzos por integrarme en la vida austriaca. Sabía que uno de mis pensamientos más frecuentes era la dificultad de no poder volver a mi país. Una idea que aunque no fuera del todo cierta, hacía que me sintiera "perdida". Parecía que la obligación de quedarse fuera del país de origen desencadenara el proceso que estaba viviendo. ¿Qué pasaría entonces con las personas que, como los refugiados, estuvieran realmente obligadas a vivir gran parte de sus vidas fuera de sus países?, ¿Se reproducirían también en ellos las mismas dinámicas que yo había experimentado?, ¿Qué harían ellos para "sentirse" cerca de sus países y autoafirmarse? De ahí, del deseo de encontrar respuestas para todas estas preguntas, nació esta investigación que me llevó a compartir durante 4 días de agosto con 11 refugiados sus experiencias en España.

\section{Introducción}

A partir de los datos recogidos en diversas entrevistas, este trabajo trata de dar los primeros pasos en el análisis de las relaciones que los refugiados establecen con Internet y la influencia que estas tienen en su identidad e interacciones sociales. Para ello, analizaremos primeramente conceptos como identidad, integración o exilio, indispensables para comprender qué es un refugiado. Seguidamente, analizaremos qué es lo que ocurre con estas realidades en el momento en el que el individuo entra en contacto con Internet. Estudiaremos si influyen o no a la hora de ponerse delante de una pantalla y 
cómo y en qué se reflejan factores como la actitud del refugiado ante el exilio, el grado de integración de éste en la sociedad, la relación y el sentido de pertenencia con su país de origen, las tensiones con las que el refugiado pueda sentir su identidad,...

Este trabajo, no es más que la búsqueda de la respuesta a una pregunta:¿cuáles son las motivaciones que llevan a los refugiados a utilizar Internet y cómo influye este uso en su identidad y relaciones con los países de origen y asilo?

\section{Marco teórico}

El estudio de los usos que los refugiados hacen de las Tecnologías de la Información (TI) es un campo que comienza a ser explorado en los últimos años, después de que durante décadas la atención de los investigadores haya estado centrada en los aspectos más legales - tales como la definición jurídica de lo que es un refugiado, de las condiciones que lo hacen susceptible de recibir asilo por un país o de los derechos que este estatus de refugiado le otorga - que la Convención de Ginebra de 1951 formuló por primera vez. Por ello, porque nos encontramos ante un campo de investigación por explorar en el que todavía está pendiente el desarrollo de un marco teórico propio, se han utilizado conceptos formulados para el estudio de otras realidades.

Existen abundantes e interesantes trabajos sobre los usos que inmigrantes y grupos en diáspora hacen de las distintas tecnologías de la información. Tal es el caso del estudio llevado a cabo por Marie Gillespie en los años 90 en Television, Ethnicity and Cultural Change en el que analiza la influencia de la televisión en una comunidad diaspórica londinense (Gillespie 1995) o el de las relaciones entre los medios electrónicos y los grupos de desplazados llevado a cabo en Modernity at large por (Appadurai, 1996).

Otros autores como Rommes, Haddon o Silverstone y Hirsch (Rommes, 2002; Haddon, 2001; Silverstone, Hirsch, 1992) se centran en los efectos que las nuevas tecnologías tienen en distintos grupos: Rommes analiza las diferencias en el uso de Internet de hombres y mujeres, Haddon la influencia que la telefonía móvil tiene en los entornos domésticos y Silverstone y Hirsch estudian los usos de la televisión en esos mismos entornos familiares.

Ante la inexistencia de trabajos que relacionen directamente refugiados e Internet, hemos seleccionado conceptos utilizados en el estudio de estos dos campos (desplazados/medios de comunicación y medios electrónicos/grupos minoritarios) para crear un marco teórico apropiado.

De los estudios de desplazados y minorías utilizaremos conceptos como "juegos de la imaginación" (work of imagination)", comunidades de sentimiento, (Appadurai, 1996) identidad de resistencia/identidad proyecto (Castells, 1998). Así como terminología utilizada en el estudio de los efectos y motivaciones relacionados con las tecnologías de la comunicación como "apropiación (appropriation)", "domesticación (domestication)", ( Rommes, 2002; Haddon, 2001; Monteiro, 1998; Baym, 1998; Silverstone, Hirsch, 1992) "formas de capital" (forms of capital) (Bourdieu, 1983).

A través de la aplicación de estas teorías al campo de los refugiados que nos ocupa, salvamos el vacío metodológico en lo que no deja de ser una propuesta para investigaciones futuras en este campo. 


\subsection{La indefinición de refugiado}

Uno de los primeros problemas a los que se enfrenta cualquier investigador que pretenda trabajar con refugiados es la ausencia de una definición cultural de la figura del refugiado. Hoy en día y más de medio siglo después, el artículo 1 de la Convención de Ginebra de 1951 sigue siendo el punto de referencia para investigadores, juristas y organizaciones humanitarias desde el que comprender, ayudar, proteger, estudiar y regular a los refugiados. Por ello, al no contar de antemano con una definición válida para nuestros objetivos, haremos un breve repaso por la historia y los textos jurídicos, con el fin de delimitar nuestro objeto de estudio.

\subsection{Identidad e imaginación}

Veremos que la construcción de la identidad se produce en contextos marcados por las relaciones de poder ante las que el individuo puede reaccionar de manera diferente: oponiéndose y rechazando ese poder (identidad de resistencia) o tratando de buscar alternativas conciliadoras (identidad proyecto) (Castells, 1998). En ese proceso de construcción de la identidad como refugiado, la imaginación (work of imagination) será uno de los "escenarios para la acción" utilizados (Appadurai, 1996) que también influirán -como sus actitudes- en la forma de apropiarse de Internet.

\subsection{Apropiación y domesticación}

Estos dos términos, que nacen de los estudios que analizan el consumo de las tecnologías modernas en el hogar y la familia, serán los que nos ayuden a entender las relaciones que establece el refugiado con la tecnología.

Por domesticación entendemos el proceso bidireccional por el que una tecnología es aceptada y modificada por el usuario para satisfacer sus propias necesidades, es decir, la tecnología es "personalizada" y en ese proceso, esa misma tecnología cambia las pautas de comportamiento de quien la utiliza:

"when a human tames an animal, both the human and the animal are affected/transformed, but also the context the animal shall participate in (for instance family life) is changed" (Levold 2001 en Rommes, 2002: 213)

Este término nos permitirá primeramente, analizar las motivaciones que llevan a los refugiados a elegir una tecnología y no otra y saber qué tipo de necesidades pretenden cubrir mediante su uso, para a partir de este análisis saber cómo afecta la integración de las nuevas tecnologías tanto a las relaciones que mantienen con sus países de origen, como a la concepción que ellos tienen de sí mismos (identidad).

Este proceso de domesticación se divide en cuatro dimensiones o fases que pueden ser estudiadas de manera independiente: apropiación (appropriation) que se produce cuando el individuo "toma posesión de un artefacto y se convierte en dueño de él" con el objetivo de satisfacer necesidades imaginadas, objectificación (objectification) mediante la cual el artefacto es expuesto por el individuo y en esta exposición "informará sobre el estatus social del individuo" para más tarde ser incorporado en sus hábitos y rutinas diarias (incorporation) que con la nueva presencia del artefacto terminarán por cambiar (conversión) (Silverstone, Hirsch y Morley 1992) o dicho en otras palabras: el individuo imagina comodidades que intentará satisfacer con la utilización de una tecnología (apropiación): 
decide aprender informática y compra un ordenador para poder utilizar Internet. Esta tecnología comenzará a tener un espacio real en su vida (objectificación) bien sea porque el ordenador se instale en la sala de estar o porque cada día se dedique un espacio de tiempo para consultar el correo electrónico. A medida que vaya utilizando el ordenador, sus hábitos, su forma de pensar y relacionarse con el mundo, cambiarán (incorporación) (Rommes 2002): conocerá a gente nueva, hará sus transacciones bancarias por Internet, dedicará menos tiempo a ver la televisión,...

\subsection{Las formas de capital}

La elección y apropiación de una tecnología está muchas veces condicionada por la posición social del individuo, por los recursos que éste tenga para elegir o rechazarla y por su situación financiera. Unos condicionantes que Bourdieu resume en lo que ha denominado como tres formas de capital: capital social, que viene a ser nuestra participación en las redes sociales y los recursos que pueden ser movilizados a través de estas redes. El capital cultural que es el conjunto de logros, las disposiciones y los valores que tiene el individuo y por último, el capital económico o los recursos financieros que están a nuestra disposición (Bourdieu 1983).

Veremos que el proceso de domesticación en su primera fase de apropiación, en la que nos centraremos especialmente a lo largo de esta investigación, es un trabajo imaginativo en el que las comodidades, las mejoras en la calidad de vida asociadas a las nuevas tecnologías, son concebidas por el individuo como objetos de deseo, que no sólo desempeñan funciones concretas, sino que además actúan como construcciones que promueven el deseo de diferenciación y significación social (Rommes, 2002).

Formulado de otro modo, utilizaremos el proceso de domesticación, centrándonos básicamente en las fases de apropiación e incorporación para estudiar cuáles son las motivaciones que empujan a los refugiados a ponerse delante de una pantalla de ordenador, cómo estas motivaciones se ven satisfechas y, en ese proceso, cuáles son las consecuencias más directas sobre su identidad como refugiados y sus relaciones reales e imaginadas con los países de origen y asilo.

\section{Metodología}

Partiendo de la base de que hay dos tipos de datos de naturaleza distinta que resultan relevantes para nuestra investigación como son por un lado, la manera en la que los refugiados utilizan Internet, y por otro lo que hemos llamado percepciones subjetivas de estos usos, consideramos adecuada la utilización de una metodología combinada de cuestionarios cerrados y entrevistas personalizadas.

En este trabajo, se ha elegido el estudio de caso como aproximación metodológica. Este tipo de aproximación al objeto de estudio es un método de investigación cualitativo adecuado para los análisis explorativos como en el que se basa esta investigación: el estudio de los mecanismos particulares a través de los cuales la identidad y la tecnología se moldean mutuamente en una situación de exilio como la de los refugiados (Rommes, 2002). 


\subsection{La pertinencia de la entrevista en profundidad}

Desde el mismo momento en el que se pensó en llevar a cabo un análisis de las relaciones refugiadoInternet se estableció como conditio sine qua non el trabajo empírico. Así, ésta investigación nunca hubiera sido posible sin los días de intensas entrevistas y largas conversaciones que mantuve con 11 refugiados. El principal motivo por el que se planteó la investigación desde el acercamiento del investigador al objeto de estudio fue la comprobación de la ausencia de otro tipo de estudios similares en los que se analizara alguno de los aspectos de las relaciones que se establecen entre refugiados e Internet. No hay teorías, estudios ni conclusiones que tomar como puntos de partida y sí todo un campo por explorar. Este vacío investigativo y la convicción de que la presencia del investigador y su implicación directa con los refugiados, "hacía poco probable que los informantes mantuvieran una identidad falsa o prefabricada" (Hine, 2000) que terminara por intoxicar nuestra investigación, fueron los que finalmente perfilaron la metodología cualitativa. Una metodología que está destinada a asegurar el ajuste entre los datos y lo que la gente realmente piensa escuchándoles hablar sobre lo que tienen en mente y que posiblilitan que el investigador cualitativo obtenga un conocimiento directo de la vida social que no está filtrado por conceptos, definiciones y escalas (Taylor, 1984) Taylor, en su defensa de la validez de la entrevista en profundidad como método de investigación cualitativo en aquellos casos en los que existe una limitación de tiempo de investigación, subraya el valor de los datos recogidos mediante este método:

"Los observadores participantes a veces "pedalean en el aire" durante semanas, incluso meses, al comienzo de la investigación. Lleva tiempo ubicar los escenarios, negociar el acceso, concertar visitas y llegar a conocer informantes. Aunque los entrevistadores pueden enfrentar problemas análogos, los estudios basados en entrevistas por lo general pueden completarse en un lapso más breve que la observación participante. Mientras que el observador participante puede perder tiempo esperando que alguien diga o haga algo, por lo general el entrevistador recoge invariablemente datos durante los períodos que pasa con los informantes. La presión por obtener resultados en los estudios subsidiados o por escribir disertaciones puede limitar severamente la cantidad de tiempo que el investigador puede dedicar a un estudio. Con las entrevistas se logra el empleo más eficiente del tiempo limitado del investigador"

Condicionados por las limitaciones de tiempo, nos hemos centrado en el estudio y análisis del trozo de realidad subjetiva que componen 11 refugiados anónimos en España. Por ello, todas las conclusiones de este trabajo las limitaremos a nuestro objeto de estudio, dejando las posibles generalizaciones para las conclusiones finales y otras investigaciones que se quieran hacer en el futuro.

\subsection{Informantes y recogida de material}

Este trabajo está basado en las entrevistas que durante cuatro días del mes de agosto de 2003 se mantuvieron con 11 refugiados en Madrid. Las entrevistas fueron abiertas o semiestructuradas, es decir, sobre un guión preestablecido, se dejó que los entrevistados hablaran y compartieran sus experiencias de manera libre. Al final de cada entrevista (que duró aproximadamente una hora), se pasó un breve cuestionario cerrado con el objetivo de recoger datos relevantes (tales como los fines y la frecuencia de uso de Internet, lugar de acceso,...) que pudieran haber sido omitidos en la conversación. 
La mayoría de las entrevistas fueron realizadas en la sede de la Comisión Española de Ayuda al Refugiado (CEAR), salvo en tres casos en los que se llevaron a cabo en la vivienda de un estudiante universitario ruandés, en la portería de un edificio de oficinas en las que trabaja un periodista colombiano y por último, en la sala de espera de un hospital en el que estaban siendo atendidas dos hermanas también de origen colombiano. En todos los casos, la conversación se desarrolló en lugares aislados para evitar que los entrevistados se sintieran coaccionados a la hora de hablar. Con el fin de realizar una recogida de datos más exhaustiva, todas las conversaciones fueron grabadas, salvo en una ocasión en la que el entrevistado se mostró desconfiado, por lo que se tomaron notas escritas.

Todos los entrevistados tienen el estatuto de refugiado, salvo dos de ellos: un zootecnista colombiano que está esperando la sentencia después de que la petición haya sido aceptada a trámite y un antiguo funcionario cubano que está amparado bajo el artículo 17.2 de la Ley de Asilo, que le permite residir en España "por razones humanitarias". Se consideró que la condición de refugiado era indispensable para la validez del estudio, ya que el análisis de los efectos que el salir de los países de origen contra la propia voluntad tiene en los refugiados es uno de los objetivos de la investigación.

Las entrevistas fueron organizadas por las responsables de los Servicios Sociales de CEAR, que fueron las que llamaron y localizaron de entre sus bases de datos a refugiados bajo dos únicas premisas: que fueran refugiados y utilizaran Internet. Características como el sexo, la nacionalidad o la edad no fueron tomadas en cuenta por no considerarse relevantes. A partir de ahí, todos aquellos refugiados que estaban disponibles durante los cuatro días en los que se llevaron a cabo las entrevistas fueron citados sin excepción hasta reunir a 11 de ellos. El hecho de que CEAR mediara entre entrevistados y entrevistador pudo producir cierto sesgo en las respuestas de los informantes que, en un primer momento, asociaron este estudio con la actividad de CEAR. Para ello, se les explicó el porqué de la investigación y se hizo constar su absoluta independencia.

Finalmente, fueron entrevistadas 11 personas de 6 nacionalidades diferentes ( 6 de Colombia, 1 de Gambia, 1 de Guinea Ecuatorial, 1 de Ruanda, 1 de Irán y 1 de Cuba), entre los que había 3 mujeres y 8 hombres y las edades oscilaban entre los 18 años del más joven y los 47 de la mayor. Sus testimonios serán utilizados a lo largo de este trabajo en el que, con el fin de preservar su intimidad, sus nombres han sido reducidos a iniciales.

\section{4. ¿Qué es un refugiado?}

A pesar de que los periódicos y televisiones se llenen casi diariamente de noticias relacionadas con movimientos migratorios, existe una gran confusión en la opinión pública entre términos como inmigrante, desplazado interno o refugiado. Una confusión que lleva muchas veces a mezclar personas y contextos diferentes y que sigue siendo uno de los mayores obstáculos para la integración de estas minorías. Con el objetivo de definir nuestro objeto de estudio, haremos un breve repaso por la evolución que, desde un punto de vista histórico, legal y religioso ha sufrido el término refugiado a lo largo de la historia. 


\subsection{El exilio a lo largo de la historia}

La historia de la humanidad comienza, según la Biblia, con un exilio: el de Adán y Eva tras ser expulsados de los Jardines del Edén por Dios. Más tarde, los israelíes huirían de la esclavitud de Egipto en busca de un nuevo hogar y el propio nacimiento de Jesucristo, según San Mateo (2:13-18), estuvo precedido por la visita que un ángel le hizo a José para decirle que huyera con su mujer y su hijo de Belén a Egipto y protegerlos del rey Herodes. Días más tardes, el monarca mandaría matar a todos los niños de Belén que tuvieran menos de dos años y José salvaría, gracias al exilio, la vida de su hijo.

El tema de la huída de la persecución es también central en el Islam: uno de los acontecimientos centrales de esta religión, la Hégira - que proviene de la palabra árabe "Hijrah", que significa exiliomarca la huída del Profeta Muhammad de la persecución en la Meca a la ciudad de Medina en el año 622 de Nuestra Era. También en las tradiciones religiosas orientales como las guardadas en el poema épico hindú Ramayana, el héroe, el rey Rama, es expulsado la víspera de su subida al trono al bosque para vivir en exilio durante 14 años.

Unida a la noción de exilio también encontramos en los distintos textos sagrados la obligación de ofrecer asilo, es decir, el acoger a las personas que buscan protección fuera de sus lugares de origen. Ya a los antiguos israelíes se les señalaba en el éxodo que "al extranjero no engañarás, ni angustiarás, porque extranjeros fuisteis vosotros en la tierra de Egipto "(Éxodo 22:11) y también en el Nuevo Testamento Jesús se identifica como un extraño "era forastero y me acogisteis" para anunciar a sus seguidores que "cuanto hicisteis a uno de estos hermanos míos más pequeños, a mí me lo hicisteis", señalando que acoger a otro ser humano es como acoger a Jesucristo (Mateo 25:35-45). A partir de aquí, la Iglesia Cristiana a lo largo de su historia ha ido promoviendo la protección de aquellos que buscaban cobijo en sus santuarios, un principio de asilo eclesiástico que fue formulado por primera vez en el Consejo de Sardis en el año 347 y que llega prácticamente hasta nuestros días con el Código de Derecho Canónico de la Iglesia Católica Romana.

También para los musulmanes el asilo es un deber religioso que es recordado a sus fieles en su lugar más sagrado. En una de las inscripciones que rodean la Kaaba en la Meca y según el Corán (14:3537) se puede leer "Señor, haz de este un lugar de asilo seguro" (Frelick 2001) y es que, tradicionalmente, cualquier individuo que buscara refugio en este lugar era protegido.

\subsection{La Convención de Ginebra de 1951}

A pesar de que, como hemos comprobado, se podría afirmar que, desde que existe humanidad ha habido seres humanos obligados a exiliarse y buscar asilo en otros lugares, habrá que esperar hasta la mitad del siglo XX para encontrar la primera definición jurídica del estatuto de refugiado. Será en la Convención que en 1951 celebró Naciones Unidas en Ginebra, el texto legal que hasta hoy día sigue siendo tomado como punto de partida por la práctica totalidad de organismos que trabajan para los refugiados. Algo que ha sido determinante a la hora de elegir este texto legal como punto de partida de este trabajo y en el que se afirma que un refugiado es todo aquel que

"debido a fundados temores de ser perseguida por motivos de raza, religión, nacionalidad, pertenencia a determinado grupo social u opiniones políticas, se encuentre fuera del país de su nacionalidad y no pueda o, a causa de dichos temores, no quiera acogerse a la protección de tal país". (Art. 1, A2) 
En esta definición encontramos algunos elementos que resultan clave para entender el contexto en el que se mueve un refugiado:

- El individuo ha sido víctima de una persecución por razones estrechamente relacionadas con su identidad como son la raza, la religión, la nacionalidad o la pertenencia a grupos sociales o políticos.

- Existe además un temor, muchas veces ligado al riesgo de perder la vida, por permanecer en el país de origen.

- Este temor hace imposible la permanencia en el país de origen lo que obliga al individuo a huir a otro país y asentarse. Se llega al país de asilo para salvar la vida, por obligación, no por elección propia.

Así, nos encontramos con seres humanos que han tenido que huir contra su voluntad de los países en los que nacieron, crecieron y en muchos casos labraron un futuro:

"Después de algunos años de formación logré un nivel de estabilidad profesional, familiar, y lo que menos esperaba era verme abocado a abandonar el país cuando tenía gran parte de mis cosas solucionadas en el inmediato futuro y en el futuro lejano. O sea, que ya tenía mi vida totalmente definida (...)Tomé la decisión porque no había otra salida, pero si por mí hubiera sido, nunca la hubiera tomado".

Lo cuenta J.B, un antiguo guerrillero colombiano que trabajaba como abogado en Colombia cuando tuvo que exiliarse en junio de 2001. Al llegar a España, estuvo varios meses haciendo todo tipo de trabajos - "obviamente, no como abogado"- en la que fue "una experiencia que le queda a uno que lo marca para toda la vida. Una etapa muy dura de mi vida en la que hice de todo. Hasta trabajar en la naranja en Valencia".

Esta huída del país de origen se da en gran parte de los casos involuntariamente y después de un largo tiempo de persecuciones y violencia. Finalmente, es el instinto de supervivencia lo que los lleva a dejar el país y así salvar la vida.

Salvar su vida de las amenazas dejando atrás el Valle del Cauca donde había trabajado como zootécnico en las comunidades de campesinos fue lo que llevó a F.C., un colombiano de 30 años, a decidir de un día para otro el venirse a España:

"Yo jamás pensé... yo quería venir a España pero de turismo, porque yo además quiero mucho a mi país, no quisiera haberme salido de allí y cada día me cuesta mucho más pensar en la posibilidad de que yo no pueda regresar a mi país y establecerme allí, pero ante la situación no solamente de seguridad, el conflicto que vive mi país, la economía, la inseguridad... todo eso te lleva a buscar el futuro en otro lugar. Quedarte allí a no poder vivir no se justifica tampoco, por mucho amor que tengas por tu patria, ¿no?"

Llegó a Madrid hace casi dos años con más compañeros con la idea fija de tramitar la solicitud de asilo en España. Todavía está a la espera de una respuesta por parte del Gobierno.

El refugiado muchas veces elige el país de asilo por proximidad cultural o lingüística, porque algún familiar o amigo resida en él o simplemente porque entrar en el país no requiera visado. Tal fue el caso de la familia de N.H., un estudiante universitario que a los 14 años vino a España desde Irán: "elegimos España porque mi tío estaba en España y con una invitación conseguimos el visado" o 
R.B., un diplomado en empresariales rwandés que llegó a nuestro país con 22 años en 1997 porque tenía una hermana monja en Madrid.

\subsection{Obstáculos a la integración}

Una vez en el país de asilo, la mayor frustración se produce en el ámbito laboral donde los refugiados (en su mayoría pertenecientes a elites intelectuales reconocidas y respetadas en sus países de origen) se ven obligados a hacer todo tipo de trabajos para subsistir.

Tal es el caso de M.S. viceministro de Gambia hasta el golpe de 1994, que se gana la vida hoy en día trabajando en una cooperativa de confección de ropa africana en Madrid. Dice que le gusta su trabajo, consciente de su suerte, aunque no deja de admitir que preferiría trabajar en campos relacionados con la política o la administración, en los que trabajó 16 años en su país. Directores de comunicación que trabajan de porteros en uno de los muchos edificios de oficinas de Madrid, profesoras universitarias que venden tarjetas telefónicas en la calle, abogados que vendimian, altos funcionarios que trabajan en polideportivos, viceministros que se ganan la vida como manipuladores de alimentos, son ejemplos de la dureza que la reinserción laboral supone par el refugiado. F.C,.que se ha quedado sin trabajo el día anterior a la entrevista, cuenta:

"ahí viene la lucha. Te enfrentas a una cantidad de cosas que... sobre todo que cuando, por lo menos yo, que en Colombia vivía cómodamente, y llegar aquí y ver que con lo que tú haces, tu trabajo, tus cosas no valen nada aquí, que tú aquí eres uno más y tienes que empezar de cero, te cuesta un poco de trabajo. Asumir esa idea y que aquí no eres nadie y que tienes que empezar de cero... es, yo creo, el bloqueo más grande que te encuentras".

R.G. ha pasado, paradojas de la vida, de ser un funcionario respetado en Cuba a no ser respetado por los funcionarios españoles: "a veces te tratan como un delincuente, cuando tú sabes lo que vales y hasta dónde puedes llegar" y aunque esta situación a veces lo deprime, él no quiere darse por vencido: "Si te lo propones, sales adelante en cualquier lugar. De forma lista. Si te lo propones, sale."

No sólo en el proceso de búsqueda de trabajo, también en el ámbito de las relaciones sociales los refugiados tienen que comenzar de cero y afrontar una realidad hostil y llena de prejuicios.

J.M, guinea ecuatoriano de 22 años, cuenta que, a su llegada a España hace 5 años, acostumbraba a saludar por la calle a la gente negra que veía. Al preguntarle la razón por la que se siente más cercano de un negro que de un blanco, dice:

“... a lo mejor influye en nosotros mentalmente una cercanía por el color... cómo quieres que te lo diga, ni yo mismo lo sé. Pero te sientes bien, mucho mejor. Porque en esta sociedad que es muy grande, la gente no se comunica mucho y el ser humano siempre intenta mantener las relaciones y comunicarse. Yo creo que es el afán de comunicarse con la gente con la que tengas una mínima cosa en común".

Ese afán por comunicarse y comprender la nueva cultura es lo que hace que el aprendizaje del español sea uno de los primeros objetivos al llegar a España como señala M.S., que nada más llegar de Gambia y después de tramitar la petición de asilo, se puso a estudiar español "porque es algo que tengo que aprender para poder vivir aquí, porque vivir aquí no es sólo vivir, también hay que poder hablar el idioma para poder comunicarse con la gente". También R.B, el estudiante rwandés, estudió 
español en sus primeros meses en España "que es lo suyo, para poder comunicarme" y N.H. con 14 años y recién llegado de Irán "decidió hablarlo bien".

Mientras aquellos refugiados que provienen de países con lenguas diferentes aprenden español, los que, como colombianos, cubanos y guinea ecuatorianos, lo conocen por ser su lengua materna, se enfrentan con la realidad de una cultura que creyeron similar a la suya y sin embargo, les da la espalda:

“ (...) es lo más difícil, cuando tú te encuentras con un país como este donde te encuentras con que todas las puertas te las quieren cerrar. Todas. Las únicas personas en las que hemos podido encontrar un apoyo es como la gente de CEAR [Comisión Española de Ayuda al Refugiado], que por lo menos están dispuestos a escucharte. Porque muchas veces con solamente el hecho de que exista alguien que te quiera escuchar, eso es mucho para ti. Puede sonar una tontería, pero que te escuchen es muy importante"

El testimonio, de F.C. no difiere mucho del de su compatriota L.M, una periodista de 27 años que salió en 2001 de Colombia después de que su padre fuera asesinado y su madre amenazada por trabajar en la defensa de los Derechos Humanos:

"vas como en una montaña rusa. A veces dices bien, no me puedo quejar en comparación con muchísima gente. $Y$ el hecho de estar aquí [trabaja como secretaria en la Comisión Española de Ayuda al Refugiado] escuchando la historia de tanta gente y de tantas dificultades y la gente sigue en pie, uno dice bueno, "estoy acá, estoy bien y vamos a seguir adelante" pero a veces sí, me pica todo. Me pica el clima, me pica la comida... me pica todo y quiero estar en Colombia. Va bajando la montaña y como que tomas fuerza para seguir adelante. Pero sí, es un poco difícil"

Puertas que se cierran, montañas rusas que suben y bajan, lugares y personas que se añoran... generan un mecanismo dentro de los refugiados que los lleva a transformar las causas del exilio, que son las que los obligan en última instancia a estar contra su voluntad fuera de su país, en los clavos ardiendo a los que se agarrarán para no rendirse y "seguir en la pelea". Unas causas que, como ya hemos señalado y analizaremos en el siguiente apartado, constituyen su identidad de refugiado.

\section{Formas de apropiación}

Hasta aquí hemos hablado de los contextos de violencia y persecución en los que se produce el exilio y de cómo estos contextos influyen en las actitudes de los refugiados a la hora de enfrentarse a la nueva cultura del país de asilo. Ahora que ya tenemos el sujeto y su entorno, pongámoslos en contacto con las tecnologías y veamos qué pasa: para qué se utilizan, cuáles son las necesidades que se quieren satisfacer mediante este uso, cómo cambian, en definitiva, sus relaciones con el uso de Internet. Hablemos pues, de apropiaciones y de los factores que las determinan.

Definíamos al principio de este artículo apropiación como la primera fase del proceso de domesticación en la que el individuo toma la decisión de introducir una tecnología en su vida con el objetivo de satisfacer necesidades imaginadas (Rommes 2002; Baym, 1998).

Necesidades imaginadas como las de R.F. que quiere "ver a mis hermanos que, según me cuentan, están envejeciendo a paso largo" y el rostro de su madre a la que "tal vez nunca la vuelva a ver cara a cara". Ante esa necesidad, R.F. planea la instalación de una cámara en su ordenador de Madrid, 
apropiarse de esta tecnología que satisfaga esa necesidad, a pesar de saber de antemano que "una cámara nunca me dará el tono exacto de sus bellos ojos verdes". Como podemos comprobar, las necesidades (R.F. desea no sólo escuchar a su familia por teléfono, sino también verla) determinan la apropiación tecnológica del sujeto (porque quiere ver, decide instalar una cámara web y no un escáner o una impresora), pero no únicamente. Existen otro tipo de circunstancias y contextos, que directa o indirectamente influirán también en la decisión de apropiación y que empezaría en el hecho de que los refugiados no pueden volver a su país.

R.F. es consciente de que no puede ver los ojos de su madre en directo, que está condicionado por un exilio que le impide volver a Colombia. Por ello, acepta este hecho y busca la manera más realista, más económica, más inmediata y accesible a sus conocimientos de satisfacer sus ganas de hacer todo aquello que por no estar en Colombia no puede hacer, como por ejemplo, ver los ojos verdes de su madre. Teniendo en cuenta sus limitaciones y necesidades, es ahí donde decide apropiarse de una cámara web. El acto de apropiación se desarrolla de manera diferente según sean el contexto y el entorno en el que se mueva el individuo, y de la capacidad que éste tenga de aceptar, rechazar o modificar una tecnología. Esta capacidad está basada en los recursos que disponga el individuo para ejercitar su poder de aceptación, modificación o rechazo (Rommes 2002) y puede ser analizada a partir de lo que Bourdieu denomina las tres formas de capital (Bourdieu 1983).

\subsection{Las formas de capital}

Para Bourdieu, todo individuo posee tres tipos de capital o poder (capital social, capital económico y capital cultural) que influyen sobre sus recursos y capacidad de movimiento dentro de la sociedad.

Siguiendo con el caso de R.F, su capital social es el conjunto de contactos reales o potenciales que tiene dentro de las redes de relaciones sociales y gracias a los cuales disfruta de una posición privilegiada dentro de la sociedad (Bourdieu, 1983). Dicho de otro modo, serían los periodistas, políticos, funcionarios, amigos, vecinos, ONGs, etc. que conoció cuando trabajó como Director de Comunicación en Medellín, en el tiempo que estuvo viviendo en un Kibutz en Israel y en los años que lleva en Madrid.

Además de esa red de amigos y conocidos que le ha permitido, entre otras cosas, seguir publicando y ejerciendo la profesión de periodista en la distancia, R.F. posee una formación que ha ido adquiriendo a lo largo de los años (embodied state) y unos títulos universitarios (institutionalized) ${ }^{\mathrm{ii}}$ que componen su capital cultural y que son los que le permitieron trabajar como periodista en el pasado y elaborar ahora los exhaustivos dossieres documentales sobre la violencia en Colombia que proyecta publicar en Internet. Por último, estaría el capital económico, que es aquel que engloba todo aquello que puede ser convertido en dinero porque el individuo tiene un derecho de propiedad sobre ello.

En el caso de R.F. su capital social (las buenas relaciones que sigue manteniendo con muchos de sus colegas en Colombia), unido a su capital cultural (que va desde su formación de periodista, su conocimiento de las legislaciones que defienden los Derechos Humanos o el saber manejar un ordenador, hasta su compromiso con sus tradiciones, raíces, etc.) y a la capacidad de movimiento que le da su capital económico, condicionan la apropiación que R.F hace de Internet: participa en foros de discusión y listas de correo que le permiten seguir el curso del conflicto colombiano, consulta periódicos en línea en los que encuentra la información necesaria para sus dossieres y utiliza el correo electrónico para intercambiar archivos con colegas de profesión. Porque R.F. mantiene una red de contactos en Colombia en el campo del periodismo (capital social), conoce la evolución del 
conflicto (capital cultural) y tiene suficiente dinero como para tener un ordenador en casa (capital económico), se apropia de una tecnología como Internet para, a través del correo electrónico y la World Wide Web, satisfacer la necesidad de "mantener viva mi cotidianeidad", la que tenía en Colombia y el exilio le arrebató.

Las tres formas de capital son dinámicas y van evolucionando en la medida en la que pasa el tiempo y el individuo interactúa con la sociedad. A veces, el refugiado ampliará su capital cultural, porque es consciente de que con ello, podrá satisfacer sus necesidades a través de la apropiación de una tecnología que no domina. Tal es el caso de M.S., ex viceministro gambiano. Con un capital social que engloba a todos los miembros del Gobierno de aquel país hasta 1994, su incapacidad de manejar Internet cuando llegó a España en 1996 redujo notablemente la calidad e inmediatez de sus fuentes de información:

"la única cosa que hacía era hablar con mis amigos de Gambia para saber lo que estaba pasando y a veces me mandaban periódicos $Y$ eso, también llega pero lento"

Por ello, decidió apuntarse a un curso de informática para inmigrantes "y ahora siempre estoy muy curioso por abrir Internet, porque ya sé que cuando lo abra voy a encontrar algo interesante". Ante las limitaciones de su capital económico, el de un refugiado padre de familia, que no le permitía instalar un ordenador con conexión en su casa, M.S. utiliza el ordenador de la cooperativa en la que trabaja para a través del correo electrónico mantener su compromiso político con Gambia:

"porque estamos aquí, pero estamos haciendo todo para poder quitar a los que están en el poder hoy. Porque no podemos decir, "si, estamos afuera, mi familia está aquí y que pase cualquier cosa que no nos interesa". No podemos decir eso. Tenemos que contribuir positivamente, bien políticamente, socialmente, económicamente... tenemos que hacer cosas buenas para avanzar la vida de los gambianos. Entonces, estamos aquí, pero nos comunicamos para ver qué podemos hacer para ayudar a los partidos de la oposición".

Organizan para ello conferencias anuales y han creado el Movement for the Restauration of Democracy in Gambia, compuesto mayoritariamente por el Gobierno en el exilio al que M.S. pertenece. Entre reunión y reunión las labores organizativas las llevan a cabo a través de Internet (convocatorias, información, dossieres, etc.). Obvia decir que si M.S. no hubiera ampliado su capital cultural, nunca hubiera podido desarrollar su compromiso político y su identidad en el exilio.

En otros casos, la limitación se encuentra en el capital económico: N.V y E.V., con una carrera política en Colombia y juristas de profesión, se dedican actualmente a estudiar para la convalidación de su título de derecho en España. Reciben una pequeña beca que les permite sobrevivir en un tiempo en el que dedican todas las horas del día a estudiar. El estudio les quita tiempo y la posibilidad de conseguir otro trabajo que ampliara sus ingresos mensuales, por lo que no pueden comprarse un ordenador ni tienen tiempo para acercarse a un sitio de acceso público a Internet. Dicen que en un futuro, en cuanto consigan su convalidación y un trabajo, un ordenador será lo primero que compren. Mientras tanto, mantienen su capital social - todos los juristas, políticos, amigos, etc. que dejaron en Colombia- a través de la única vía que les es accesible: el teléfono.

Gracias al capital social de la familia, N.H., sus padres y su hermana, pudieron viajar conjuntamente a España desde Irán, R.G. pudo quedarse en casa de una amiga en Madrid cuando decidió no regresar a Cuba y F.C., que llegó con otros compañeros de trabajo, tramitar la petición de asilo inmediatamente. Todos ellos tenían una red de contactos en Madrid que les ha ayudado a integrarse 
más rápidamente en España. Todos ellos, utilizan hoy en día Internet mayoritariamente para comunicarse con amigos españoles y buscar trabajo en España. Pero no siempre es así. Otros refugiados como J.B. que no conocía a nadie en España, sigue unido a Colombia gracias a Internet "me siento directamente conectado con lo que está pasando allá" - y, a pesar de que han pasado ya más de dos años desde que llegó a Madrid, no tiene intención de integrarse: "No" (rotundo) "y lo digo con convencimiento, no es una elucubración del momento".

\subsection{La brecha digital}

A veces, existe un factor externo al refugiado como es el acceso tecnológico en su país de origen que influirá también en las apropiaciones que este terminará llevando a cabo. Un cuarto capital que se situaría entre el capital económico y el capital cultural y que está compuesto por la posesión/acceso a una tecnología y la competencia para utilizarla de un individuo o colectivo. La exclusión tecnológica, en el lenguaje de la Globalización, se designa como brecha digital o digital divide ${ }^{\mathrm{iii}}$ y conlleva la división de los seres humanos entre aquellos que tienen acceso a la información (haves) y aquellos que no (have-nots) (Wresch, 1996).

Ninguno de los refugiados de origen africano conocía Internet antes de llegar a España. Ahora, todos ellos utilizan esta tecnología con regularidad. A J.M. le enseñó un amigo en sus horas libres; R.B. y M.S aprendieron en academias. En ninguno de los casos les sirve para comunicarse directamente con sus familiares y amigos en Gambia, Guinea Ecuatorial o Ruanda (para eso utilizan el teléfono), pero sí para mantenerse informados mediante periódicos y radios en línea de la evolución de los conflictos que los obligaron a exiliarse. En cada caso, se han apropiado de la tecnología que, dentro de las limitaciones del entorno, mejor satisface sus necesidades de recibir información de su país y mantenerse en contacto con los seres queridos.

R.G. sufre desde que llegó a Madrid las consecuencias de la brecha digital. En su país, Cuba, los particulares no tienen acceso a Internet que él asegura que está penado y el teléfono es muy caro. Piensa en su país y su familia todos los días y es a su madre "la mejor del mundo mundial" a quien más echa de menos. Eso "le golpea muchísimo". Por ello, R.G. se ha apropiado de una tecnología como el video para sentirla cerca. Cuenta emocionado que en su cumpleaños le mandó una postal y que días después recibió una cinta con su madre abriéndola. No suelen ser los únicos vídeos. Cada vez que alguien viene o va a Cuba, le suelen traer videos con las gentes, su familia, las calles de la Habana. Esa es su manera de sentirse en su país:

"Cuando veo un video o hablo con ellos los siento tan cerquita como si me hubiera ido allá a Cuba (...)Los videos me ayudan muchísimo. Te inyectan muchísimo."

A menudo, la apropiación tecnológica contribuye a sobrellevar la añoranza de la patria y los seres queridos, al convertirse en el canal de intercambio de información entre el refugiado y su país. La existencia de Internet, el teléfono o los vídeos, consiguen que a pesar del exilio y la distancia geográfica, el refugiado se siga sintiendo parte de la comunidad a la que pertenecía antes de verse obligado a huir de su país. En este proceso de seguir sintiéndose parte de una comunidad son tan importantes las apropiaciones tecnológicas, como los juegos de la imaginación. 


\subsection{Los juegos de la imaginación}

Cuenta el antropólogo de origen indio Arjun Appadurai en su libro Modernity at large que los medios electrónicos y los movimientos migratorios en la Modernidad, han provocado una ruptura que ha redefinido el papel de la imaginación (work of imagination) en nuestra sociedad. La imaginación ya no es más un modo de huir de la realidad sino un espacio de contestación desde el que afrontarla. Appadurai basa su afirmación en tres cambios que el binomio medios de comunicación-desplazados ha provocado en la función de la imaginación en la sociedad moderna:

- Primeramente se ha producido una popularización. La imaginación ha dejado los contextos del arte, de los mitos y rituales para pasar a ser parte de la cotidianeidad y la vida diaria de muchos individuos. Esa vida diaria de la que, durante siglos, había estado aislada.

- La imaginación se ha convertido en escenario para la acción sobre nuestro entorno en oposición a la fantasía que genera vías de huída de esa realidad

- Los medios de comunicación posibilitan un uso colectivo de la imaginación que genera "comunidades de sentimiento", un grupo que comienza a imaginar y sentir cosas a la vez.

Comunidades de sentimiento que en nuestro caso, hemos visto cómo se generan en la utilización de las webcams por parte de las comunidades de refugiados a nivel familiar. Tal es el caso de L.M, que semanalmente encuentra al resto de su familia, la que se quedó en Colombia, en el salón de su casa de Madrid, haciendo de la pantalla del ordenador una ventana mágica que une en sus imaginarios una familia separada por miles de kilómetros. L.M no tiene dudas en afirmar que lo de los encuentros a través de la cámara web:

"Es lo mejor (se ríe y no puede hablar) porque es increíble... porque a veces hay reuniones y entonces vemos que están brindando o tomándose un vino y entonces decimos, "bueno, vamos a brindar todos" y nosotros sacamos el vino y brindamos y nos decimos chistes y se va asomando cada uno... y es como... es increíble que ves a la gente y dices, "iquiero estar allá!" es una sensación un poco de impotencia porque quieres estar en ese sitio y alegría un montón. Todo el tiempo, si los has visto hace ocho días te da alegría volverlos a ver".

Crean estos encuentros muy frecuentemente y siempre en las fiestas. Va a ser el cumpleaños de su abuela dentro de poco, todos se van a juntar en Colombia y ya están pensando cómo hacer lo de la cámara web, que no es más que una manera de que la familia participe en la distancia de un evento familiar e imaginar que la distancia geográfica que los separa no existe. También hablan por teléfono, pero con la webcam "pues estás más cerca, si los veo es como si te estuviera viendo a ti acá. Aunque no te pueda tocar ni darte un abrazo, pero te estoy viendo y estoy viendo que el tiempo también va pasando para ti. Porque a veces uno se queda con el recuerdo de Colombia que está ahí, pero está como congelado, como que a veces piensas que se ha parado y resulta que no" "Con el Internet es verlos, es tener la imagen viva ahí" Pone el ejemplo de sus primos, que van creciendo y están ya en la adolescencia. También se mandan vídeos de las gentes, las calles de Bogotá, algo que ella también señala como importante para recordar. En el núcleo familiar existe la clara determinación de no olvidar de dónde vienen.

Llama la atención que, a pesar de la distancia, se crean atmósferas de tipo familiar en las que se mantienen las costumbres: tal es el caso de la familia de N.H., que una vez por semana se 
encuentran a través de la Red con sus amigos de familia en Irán y que, cuando lo hacen, reproducen las costumbres familiares en las que las mujeres no se cubren, por ejemplo.

F.C, que mantiene básicamente el contacto con su familia a través del teléfono, a veces se comunica con ellos por videoconferencia. Dice que es "espectacular" la sensación riéndose a carcajadas. Que se ríen mucho, que se hacen poner de pie, para verse gordos, flacos, cómo les cambió la cara,... y se ríen todo el tiempo. Unos momentos muy preciados para este colombiano que admite que "mantengo mi país vivo dentro de mí directamente a través de mi familia; sabiendo que están allí, tengo vivo mi país". El núcleo familiar como comunidad de sentimiento que posibilita que él se sienta, imaginadamente arraigado. Un acto imaginado que tiene sus consecuencias en el día a día de F.C. reforzando su identidad de refugiado, arraigándolo a un lugar imaginado como Colombia que no es real en su día a día pero al que, sin embargo, se siente arraigado gracias al uso de Internet. Este sentirse de un lugar es el punto de partida en su nueva vida en España y una referencia constante para reconocerse a sí mismo y seguir adelante: la imaginación se ha convertido en un campo de acción sobre la realidad.

En aquellos casos en los que en los países de origen existe una inaccesibilidad a las TI, la música, las fotografías, los objetos típicos e incluso los sueños, se convierten también en elementos a través de los cuales los refugiados desarrollan la imaginación:

“(...) yo siempre que sueño con mi familia en Irán me levanto llorando, pero eso no lo puedo evitar. En los sueños llegas a lo más profundo de tu ser sin quererlo, porque allí ya no existe la doble cara o lo que suele tener la gente a la luz del día, cuando está despierto. Yo intento muchas veces por la nostalgia y todo eso evitar recordar ciertas cosas, pero es un intento muchas veces fallido. Porque es una cosa que está dentro".

Una cosa que está dentro y en lo más profundo de tu ser. Así es como N.H. a sus 18 años intenta poner en palabras lo que Irán supone en su vida. Un motivo para la nostalgia del que no se puede huir y parte de su historia. Hasta que tuvo que salir de Irán, esa historia la labraba cada día yendo al colegio o visitando el estudio de arquitecto de su padre. Ahora, en el exilio, ha sustituido las tardes con los amigos en Irán por las videoconferencias, los paseos por Teherán con los sueños y las comidas persas por algún que otro plato que, de vez en cuando, cocina su madre en Madrid. El exilio ha cambiado los contextos y el entorno de N.H. Un exilio fortuito ante el que ni él, ni el resto de refugiados pueden remediar, porque no depende de ellos. Pero saben que les queda un resquicio de libertad: el de imaginar y alimentar esa imaginación a través de las tecnologías y mantenerse así, unidos mediante el sentimiento a un país del que nunca quisieron salir. Pero esta vez, de ahí no tendrán que exiliarse.

\section{Identidad}

Cuando las redes disuelven el tiempo y el espacio, la gente se ancla en los lugares y recuerda su memoria histórica.

Manuel Castells

Después de cuatro intensos días hablando con los refugiados, escuchando sus historias, compartiendo sus proyectos de futuro, que en cada uno de ellos, como sus biografías, eran distintos, descubrí que había un nexo en común que los unía. Algo que en palabras de F.C sería querer "seguir 
dando la lucha hasta el día que diga ya perdí todas mis fuerzas y energías". Seguir adelante a pesar de que la víspera de nuestra entrevista había sido despedido de su trabajo por enésima vez y sin más explicaciones, del frío de Madrid al que no se termina de acostumbrar R.F y que le hace extrañar aún más si cabe Medellín, de las ganas de R.G. por caminar por el malecón de La Habana, de las esperanzas de M.S. de que la paz llegará algún día finalmente a Gambia. Y en esa batalla casi diaria a la que se tienen que enfrentar, existe un "ancla" - recurriendo al poder de la metáfora que encabeza este apartado - que les permite mantenerse a flote y no hundirse: el aferrarse a los lugares (geográficos o imaginados), recordar su memoria histórica y reafirmar sus identidades en el exilio para con ello, dar un sentido a sus vidas. Para Castells la identidad es la fuente de sentido y experiencia para la gente. A través de un proceso de interiorización y autodefinición, de un mirarse para adentro, el individuo encontrará ese sentido que no es más que "la identificación simbólica del objetivo de su acción" (Castells 1998), es decir, los porqués que se esconden detrás de su manera de actuar.

Tal es el caso de M.S, que a sus 43 años hace, del sentirse de un país que desde hace 7 años mantiene vivo en su imaginación, la razón para seguir confeccionando ropa cada día en Madrid:

"el sentirse gambiano es algo por lo que tú te puedes levantar cada día. Yo nací en Gambia, crecí en Gambia, yo he hecho todo de mi vida en Gambia. Es el país que yo conocía y allí también viven todos mis amigos queridos. Tu país es tu país. Si yo puedo adquirir mucho dinero, voy a pensar en ir a mi país, porque es mi país. Es el país que quiero ver en paz (...) Quiero ver a mi país como un país tranquilo, democrático, avanzado. Yo tengo la nacionalidad (española). Si me quitan los papeles, no soy español. Pero en mi país, pueden quitarme todo, pero no pueden quitarme la nacionalidad, porque soy de allí (...)Mi país es mi país"

La construcción de las identidades utiliza materiales de la historia, la geografía, la memoria colectiva y las fantasías personales y son los individuos los que procesan todos estos materiales y los reordenan según sus determinaciones y proyectos (Castells, 1998). Para L.M., su país, Colombia, del que salió hace dos años, sigue siendo el punto de referencia para no olvidar su pasado, seguir creyendo en el presente y soñar con el futuro:

"Es todo. Es mi pasado porque mis raíces están allá, mi historia está allá, porque no he querido tampoco conscientemente salir y proyectar mi vida en otro país que no hubiera sido Colombia antes de venir. Es mi presente porque estoy todos los días iquiero ir, quiero ir, quiero ir!, extraño mi gente, extraño la música, la comida, el poder ver a mis primos que han nacido cinco y no los conozco... y entonces como quiero estar al lado. $Y$ es mi futuro porque, si alguna vez en la vida quisiera regresar, si las cosas marchan mejor. Si estoy viejita, tener ochenta años y tener una casita y estar tranquila que nadie me conozca, sí algún día. Pero tengo que ser consciente también que estoy ahora acá"

Partiendo de la afirmación de que la construcción social de la identidad siempre tiene lugar en un contexto marcado por las relaciones de poder, Castells propone tres formas y orígenes de construcción de la realidad entre las que se encuentran lo que él denomina identidad de resistencia e identidad proyecto. Estos dos tipos de identidades están directamente determinadas por la actitud que los actores que se encuentran en posiciones/condiciones devaluadas por la lógica de la dominación mantienen. Una actitud que puede ser de resistencia y atrincheramiento o de proyección de una nueva realidad más integradora (Castells 1998). 


\subsection{Identidad de resistencia}

Como hemos señalado, este tipo de identidad es generada por aquellos grupos marginados que crean trincheras de resistencia basándose en principios diferentes u opuestos a los que impregnan las instituciones de una sociedad. Encuentran en la afirmación de la diferencia con el resto, con el mundo que les rodea, con el país en el que viven, la propia identidad, la esencia de su yo. En la realidad que investigamos, esta resistencia se da con mayor frecuencia en el núcleo familiar del refugiado en el que se mantienen vivas las tradiciones, la lengua, la gastronomía, los recuerdos, del país de origen hasta el extremo. En casa N.H. habla persa, a pesar de que sus padres y su hermana tiendan a hablar en español, porque él "lo considera una riqueza personal que no quiere perder", L.M. y sus hermanas, cada vez que en el supermercado encuentran un producto de su país, lo compran "Ios plátanos... colombianos, el café colombiano..." y compran en los locutorios "que es donde más se consigue" productos típicos de Colombia, "cosas que después tú dices: estoy en la gloria (se ríe)". En casa de J.M. también se mantienen sus orígenes guinea ecuatorianos a través de la música, la comida, y eso hace que si " me siento en casa, me siento bien. Cuando estoy en casa estoy bien. Pongo música guineana y africana. Me encanta la música africana, de hecho, salgo por discotecas africanas". Discotecas a las que acuden mayoritariamente africanos con los que incluso comparte una lengua, el pichi, hablada en el África ecuatorial y que él aprendió al entrar en contacto con otros africanos en España.

Esta búsqueda de la identidad propia en la oposición con el país de asilo y su cultura, encierra a menudo una actitud mucho más integradora y proyectiva. El propio J.M., poco después de hablar de la música y las discotecas africanas, hacía esta matización con respecto a la comida: "como comida africana, pero europea también porque me tengo que acostumbrar poco a poco" y es entonces, cuando vuelve a asaltarle la necesidad de resistirse "pero tampoco puedo llegar a Europa y después olvidarme de dónde soy. Porque intento mantener mi identidad... que es un sentimiento, es que soy guineano, me siento... toda mi familia está nacionalizada española menos yo". Al final, y a pesar de que a sus 20 años intenta mantener vivo ese sentimiento que le dice que es guineano, J.M. termina por reconocer que ya no es el mismo que llegó hace cinco años a Madrid:

"Yo me siento guineano, pero tengo ya demasiada influencia europea. Lo noto en la forma de ser, en las reacciones. He cambiado un montón. Me doy cuenta de que no soy el mismo que llegó. A parte de que han pasado los años, la gente con la que trato es diferente, es un mundo diferente".

Esta toma de conciencia de que el mundo, la vida, las costumbres, en los países de exilio son diferentes, como en el caso de J.M. lleva al refugiado a pendular entre la identidad de resistencia, que hace de la diferenciación su razón de ser y la identidad de proyecto, que busca en esas diferencias razones para trazar puentes.

\subsection{Identidad proyecto}

Existen otras maneras de reaccionar ante la diferencia y la exclusión social además del atrincheramiento y la oposición. Personas que ven en la estigmatización social de la que son objeto el mejor motivo para generar un nuevo proyecto de sociedad. Basándose en los materiales culturales de los que disponen, construyen una nueva identidad que redefine su posición en la sociedad y la estructura social. Es lo que Castells denomina identidad proyecto (Castells 1998) y la explicación de actitudes como la de F.C: 
"No voy a decir que estamos "españolizados", porque no me gusta esa palabra. Yo siempre seré colombiano, pero sí he querido adaptarme a las condiciones españolas, sin que eso signifique que ya no quiera saber nada de mis costumbres colombianas. De vez en cuando nos preparamos un plato de comida colombiano, pero tratamos de adaptarnos a las condiciones de vida de aquí. Casi no tenemos amigos colombianos. Muy pocos. Estamos muy metidos en el rollo de España y eso es lo que queremos también"

También R.G., desde que llegó a Madrid intenta mezclarse con la cultura española sin renunciar por eso a sus orígenes cubanos. No se relaciona con cubanos desde que llegó a Madrid hace un año y medio "porque no ha surgido" no va a locales cubanos, "no me apetece por ahora", dice que está liado con historias suyas para terminar diciendo que :"A veces me gusta integrarme también mucho, conocer la cultura del país en el que estoy, la gente, por qué son así..."

Esta actitud abierta e integradora es un granito de arena que contribuye en el día a día y de manera anónima a la reinvención de las relaciones entre los españoles y los refugiados. Una actitud que se ve reflejada en la decisión de ciertos refugiados de construir sus identidades mezclándose en los países de asilo y que paulatinamente tiene su efecto sobre las estructuras sociales. Este proceso culminará en la transformación de la sociedad como la prolongación de ese mismo proyecto (Castells, 1998) que en este caso sería la igualdad de oportunidades de todos los seres humanos en una sociedad multicultural y multirracial.

Cada tipo de proceso de construcción de la identidad conduce a un resultado diferente en la constitución de la sociedad. La identidad de resistencia conduce a la formación de comunas o comunidades, el tipo más importante de construcción de la identidad en nuestra sociedad. Se basa en la creación de formas de resistencia colectiva contra la opresión, que de otro modo sería insoportable para los integrantes de estos grupos. Por su parte, la identidad proyecto produce sujetos que, según Alain Touraine, se mueven por el deseo de ser un individuo, de crear una historia personal, de otorgar sentido a todo el ámbito de las experiencias de la vida individual (Touraine 1995 en Castells 1998: 32)

\section{Conclusiones}

Siguiendo con las metáforas, podríamos concluir que Internet es el espejo en el que se refleja la actitud del refugiado ante el exilio. Una actitud que podría ser resumida en tres palabras: aceptación, seguridad y esperanza; aceptación del pasado, seguridad ante el presente y esperanza para el futuro.

Para muchos refugiados, las TI son una vía de desahogo de las secuelas que las duras circunstancias que rodean el exilio dejan en ellos. Y esto es así porque, como hemos analizado, este medio electrónico posibilita la creación de comunidades de sentimiento y espacios de contestación como en ningún otro momento de la historia, a través de los periódicos que informan al refugiado de lo que ocurre diariamente en su país, de las cámaras web que transforman la pantalla del ordenador en ventanas mágicas que comunican hogares separados por miles de kilómetros o del correo electrónico mediante el cual poder seguir desarrollando la labor profesional anterior al exilio. En cada caso y dependiendo de su capital y sus necesidades, el refugiado se apropiará de alguna de estas herramientas con las que afrontar el exilio. Posteriormente y gracias a la ruptura que provoca Internet en los ejes espacio-temporales, recuperará la libertad de contestación (no olvidemos que en su mayoría los exiliados son personas incómodas en sus países por lo que piensan y dicen) y la 
posibilidad de permanecer en la comunidad de la que el exilio físico lo expulsó. Un hecho que hará que el refugiado se vuelva a sentir arraigado.

La aceptación del pasado traerá estabilidad y seguridad al presente, que volverá a llenarse de sentido gracias al ancla de la memoria histórica. Desde ese momento, el refugiado volverá a tener puntos de referencia a partir de los cuales re-construir el mundo y re-construirse a sí mismo y proyectarse hacia un futuro dominado por la esperanza:

"Apenas ahora que estoy concluyendo mis archivos, estoy asimilando que durante muchos años viviré en este país. No vine aquí como inmigrante. Vine de tumbo en tumbo, buscando algo de vida. Despacio, me voy rehaciendo física y mentalmente. Estoy cerrando el duelo del desarraigo. Aunque no soporto el invierno, estoy construyendo rutinas, he vuelto a sentir la noción de estabilidad. Que el mundo bajo mis pies no se está deshaciendo. Mi fe, mi deseo, es que España no se desmorone bajo mis pies, porque ésta es mi última frontera" (R.F. periodista colombiano en el exilio)

Esta es seguramente la conclusión más importante a la que hemos llegado en este trabajo que, si deja constancia de algo es de lo mucho que aún queda por analizar en el campo de las relaciones refugiados-identidad-Internet. Unas relaciones que, a medida que vayan siendo estudiadas, creemos que potencialmente podrían ser fuente de estabilidad y esperanza para muchos de los más de 20 millones de refugiados ${ }^{\text {iv }}$ que hay en el mundo. La misma estabilidad que los 11 refugiados a los que se entrevistó a lo largo de este trabajo han encontrado.

Se abre una línea investigativa interesante en el estudio de las conexiones entre las formas de capital de Bourdieu y las apropiaciones de los refugiados. A este respecto, podríamos hablar de dos fases (antes y después del exilio) en la evolución de los capitales de los refugiado y que los diferenciarían entre aquellos capitales que poseían antes del exilio y los que poseen después de él y que no siempre se corresponden. Las posiciones social y económica en el país de origen, así como el nivel de estudios con los que llega el refugiado al país de exilio, serán clave no sólo en sus apropiaciones, sino también en la readaptación de sus capitales social, económico y cultural en el nuevo país. Así, la posición social que el refugiado tenía antes del exilio, sus posesiones materiales y sus conocimientos, serán muchas veces la base para la readaptación de esos capitales en el nuevo escenario que es el país de asilo. $Y$ es en ese proceso precisamente donde las tecnologías y las apropiaciones del refugiado cobran especial importancia. En este contexto, aquellos refugiados que provienen de países en los que el acceso tecnológico es aún restringido, tendrán más dificultades a la hora de trazar puentes entre "lo que poseían y eran" y lo que "poseen (poseerán) y son (serán)", pudiéndose hablar de la existencia de una brecha digital dentro del colectivo de refugiados que influirá también en las apropiaciones que estos harán. Estos desequilibrios son los que, a primera vista, parecen más difíciles de salvar, ya que a diferencia de los capitales económico, cultural y social, forman parte de estructuras globales que trascienden al propio individuo. Investigaciones futuras podrán arrojar luz en este asunto de vital importancia para la integración de los refugiados.

Para el futuro queda también el estudio de los motivos que llevan a ciertos refugiados a no utilizar Internet, es decir, de lo que serían las no apropiaciones de los refugiados. Este análisis resultará interesante para comprender no sólo las actitudes de los refugiados que se mantienen off line, sino el papel que aquellos que, como nuestros informantes, sí hacen uso de Internet, juegan dentro del colectivo de exiliados. Así mismo, temas como la influencia de Internet en la creación de identidades ya no individuales sino de grupo, el mantenimiento de las interacciones familiares a través del uso de 
las cámaras web o la descripción de las dinámicas internas de las comunidades de sentimiento, quedan abiertos para posibles investigaciones.

Mientras tanto, miles de refugiados en todo el mundo seguirán diariamente llenándose de esperanza, gracias a unos cuantos bits que circulan por unas autopistas de la información que, afortunadamente, no entienden de fronteras ni exilios.

Donostia - Viena, septiembre de 2003

\section{Referencias}

Appadurai, A. (1996) Modernity at Large: Cultural Dimensions of Globalization. Minneapolis. University of Minnesota Press.

Batinic, B., Ulf-Dietrich, R., Bosnjak, M. (Ed.) (2002) Online Social Sciences. Seattle-Toronto-BernGöttingen. Hogrefe \& Huber Publishers.

Baym, N. (1998) "The emergence of ON-Line Community". En: Steven, G. (Ed.) Cybersociety 2.0. Revisting Computer Mediated Communication and Community. London. SAGE Publications.

Bourdieu, P.(1983) "Ökonomisches Kapital, kulturelles Kapital, soziales Kapital." En Kreckel, R.(Ed.) Soziale Ungleichheiten (Soziale Welt, Sonderheft 2). Goettingen. Otto Schartz \& Co. 183198.

Castells, M (1998) La era de la información. Vol. 2 El poder de la identidad. Barcelona. Alianza Editorial.

ECRE (European Council on Refugees and Exiles) (2000) Bridges and Fences to integration: refugee perceptions of integration in the European Union. En http://www.refugeenet.org/community/bridges.html (Septiembre de 2003)

Frelick, B. (2001) "Evolution of the term Refugee". En: http://www.refugees.org/news/fact sheets/refugee definition.htm (Septiembre de 2003)

Gillespie, M. (1995) Television, Ethnicity and Cultural Change. London. Routledge.

Hine, C. (2000) "Internet as Culture and Cultural Artefact". Virtual Ethnography. London. SAGE Publications. 14-40

Levold, N (2001) "Doing gender' in Academia: The domestication of an information-technological researcher-position". En: Glimell, H. , Juhlin, O. (Ed.) The Social Production of Technology; on the everydaylife with things. Goteborg. BAS Publisher. $133-158$.

Meyrowitz, J. (1985) No sense of place: the impact of electronic media on social behavior. New York y Oxford, Oxford University Press.

Monteiro, E (1998) "Living with technology" En: Scandinavian Journal of Information Systems, 10(1\&2). Goteborg, 249 - 254. En: http://www.idi.ntnu.no/ ericm/SJIS.domestic.html (Septiembre de 2003) 
Papalekas, J. C. (Ed.)(1989) Kulturelle Integration und Kulturkonflikt in der technischen Zivilisation. Frakfurt/Main- New York. Campus Verlag.

Rommes, E. (2002) Gender Scripts and the Internet. Enschede. Twente University Press.

Silverstone, R. and Hirsch, E. (1992) Consuming technologies. Media and information in domestic spaces. London. Routledge.

Taylor S.J, R. Bodgan (1984) Introducción a los métodos cualitativos de investigación. La búsqueda de significados. Barcelona. Paidós Ibérica.

Treumann, K. P. (et al) (2002) Medienkompetenz im digitalen Zeitalter. Wie die neuen Medien das Leben und Lernen Erwachsener verändern. Opladen. Leske + Budrich.

Wresch, W. (1996) Disconnected: Haves and Have-Nots in the Information Age. Rutgers University Press.

Zdruzenie Sudcov Slovenska (1999) Basic Legal Instruments concerning refugees. Bratislava, The Association of Slovak Judges.

' El artículo 17.2 de la Ley de Asilo establece que, «por razones humanitarias o de interés público podrá autorizarse, en el marco de la legislación general de extranjería, la permanencia del interesado cuya solicitud (de asilo) haya sido inadmitida a trámite o denegada, en particular cuando se trate de personas que como consecuencia de conflictos o disturbios graves de carácter político étnico o religioso, se hayan visto obligadas a abandonar su país y que no cumplan los requisitos a que se refiere el número 1 del artículo 3 de esa Ley (causas que justifican la concesión del asilo)». Ley de Asilo 9/1994, de Modificación de la Ley 5/1984

ii Bourdieu define el capital cultural como "el conjunto de tradiciones, mitos y creencias, lenguaje, relaciones sociales, modos de producción y productos inmateriales (literatura, pintura, danza, música, etc.) y materiales, específicos a una determinada comunidad" (Bourdieu, 1983) Este capital se encuentra en tres estados: corpóreo, objectificado e institucionalizado. El capital cultural en "estado corpóreo" es el legado de conocimiento que tiene un sujeto y que se encuentra materializado en su cuerpo, por eso el término embodied state (estado corpóreo). La adquisición de este conocimiento le supone tiempo y esfuerzo al individuo y al igual que el desarrollo de la musculatura o conseguir un buen bronceado, no puede ser hecho por nadie más que él. A diferencia del dinero, no puede ser transmitido, cambiado o regalado. El conocimiento puede estar también materializado en bienes culturales (objectified) como la pintura, los medios de comunicación o los instrumentos musicales. En estos casos, el capital cultural sí es transmisible. Finalmente, existe otro tipo de conocimiento que se encuentra institucionalizado en credenciales académicos o diplomas (institutionalized) que permite la conversión del capital cultural en capital económico (una persona con títulos será más valiosa que una que no, podrá acceder a un mejor sueldo, etc.).

iii "The term 'digital divide' describes the fact that the world can be divided into people who do and people who don't have access to - and the capability to use - modern information technology, such as 
the telephone, television, or the Internet. The digital divide exists between those in cities and those in rural areas. For example, a 1999 study showed that $86 \%$ of Internet delivery was to the 20 largest cities. The digital divide also exists between the educated and the uneducated, between economic classes, and, globally, between the more and less industrially developed nations" (Whatis.com, 2003) En: http://whatis.techtarget.com/definitionsCategory/0,289915,sid9_tax696,00.html (Septiembre 2003) iv Número de refugiados bajo mandato del Alto Comisionado de las Naciones Unidas el 1 de enero de 2003. Fuente: http://www.unhcr.ch/cgi-bin/texis/vtx/statistics 